\title{
Stem/Progenitor Cells, Atherosclerosis and Cardiovascular Regeneration
}

\author{
Olena Dotsenko*
}

Department of Cardiac and Vascular Surgery, St. George's University of London, London, UK

\begin{abstract}
Regenerative cell based therapy has potential to become effective adjuvant treatment for patients with atherosclerotic disease. Although data from animal studies support this notion, clinical studies undertaken in patients with acute and chronic coronary artery disease do not conclusively demonstrate benefits of such therapy. There are many questions on the stem cell translational roadmap. The basic mechanisms of stem cell-dependent tissue regeneration are not well understood. There is a debate regarding characterization of specific cell types conferring therapeutic effects. In particular, the role of endothelial progenitor cells as a specific reparative cell subtype is questioned, and the role of myeloid cell linage in fostering of vasculo- and angiogenesis is being increasingly appreciated. Intense discussions surround the place of stem/progenitor cells in atherosclerosis progression, plaque destabilization and vessel remodeling. This paper summarizes the current knowledge on the regenerative stem/progenitor cell definitions, mechanisms of stem cell trafficking, homing and their involvement in atherosclerosis progression.
\end{abstract}

Keywords: Stem cells, atherosclerosis, regenerative therapy.

\section{INTRODUCTION}

Atherosclerotic heart disease remains one of the major causes of morbidity and mortality worldwide. Although progress with heart revascularization techniques is enormous, many patients, particularly, those with microcirculatory disease, are not good candidates for coronary angioplasty and bypass graft surgery [1]. Post-angioplasty restenosis and graft disease substantially limit long-term benefits of heart revascularization procedures [2]. Stem/progenitor cells, characterized by capacity for self-renewal and differentiation into different cell types, bear potential for organ regeneration in various pathological states [3]. Application of stem cell-based treatment in clinical cardiology could improve standards of care for many patients.

In 1997, Asahara et al. have reported that bone marrow derived cells, presumably, stem/progenitor cells, harvested from peripheral blood and expanded in vitro, are able to enhance neovascularization of ischemic tissues in mice [4]. Since then, various cells transplantation regiments have been evaluated in studies using different animal models of tissue ischemia and vascular injury [5-7]. Overall, preclinical work had generated the body of supportive data [3]. However, the results of clinical studies undertaken in patients with acute myocardial infarction and in chronic post-infarction phase of disease do not conclusively demonstrate benefits of cell therapy [8]. The reasons for this are not clear. It is difficult to compare individual studies as they differ in methodology (cell sources and dosages, routes and time points of cell delivery, heterogeneity of study subjects and outcome

*Address correspondence to this author at the Department of Cardiac and Vascular Surgery, St. George's University of London, London, UK;

Tel: 0044 (0) 208725 3946; Fax: 0044 (0) 208725 5173;

E-mail: dotsenko_2000@yahoo.com measures). However, results of chronic post-infraction studies are less supportive for stem cell therapy then acute myocardial infarction studies. Compared to chronic disease, several trials in acute phase of myocardial infarction found that cell treatment significantly improved left ventricular function [9]. The effect, however, was transient. So far only one study reported improved left ventricular contractility at one year after cell therapy [10].

Many questions on the stem cell translational roadmap remain to be answered. The basic mechanisms of stem celldependent tissue regeneration, including details of stem cell trafficking and tissue engraftment are not well understood [11]. It is not clear whether effects of endogenous mobilized stem cells and exogenously administered cells are different. Furthermore, despite all efforts, the specific cell types conferring therapeutic effects have not been yet defined. Intense debate is focused on definition of specific markers of endothelial and other vascular progenitor cells $[12,13]$. The role of myeloid cell linage in fostering of vasculo- and arteriogenesis is increasingly appreciated [14-16].

Experimental studies have shown that transplanted stem cells gave rise to smooth muscle cells of neointima and media of recipient animal vessels $[17,18]$. Plaque neovascularization, induced by pro-angiogenic stem cells contributes to plaque growth and, in some cases, instability [19]. Autopsy studies in humans have revealed presence of stem/progenitor cells in both stable and unstable atherosclerotic plaques [20]. Therefore, stem/progenitor cells could not only play a role in tissue revascularization, but also participate in atherosclerosis progression, plaque destabilization and vessel remodeling [21] (Fig. 1). In the context of therapeutic application, there is a pressing need to define factors which govern stem cells involvement into atherosclerosis and factors, which regulate stem cell-dependent tissue reparation. Unfortunately, there is still a lack of appropriate study models to investigate func- 


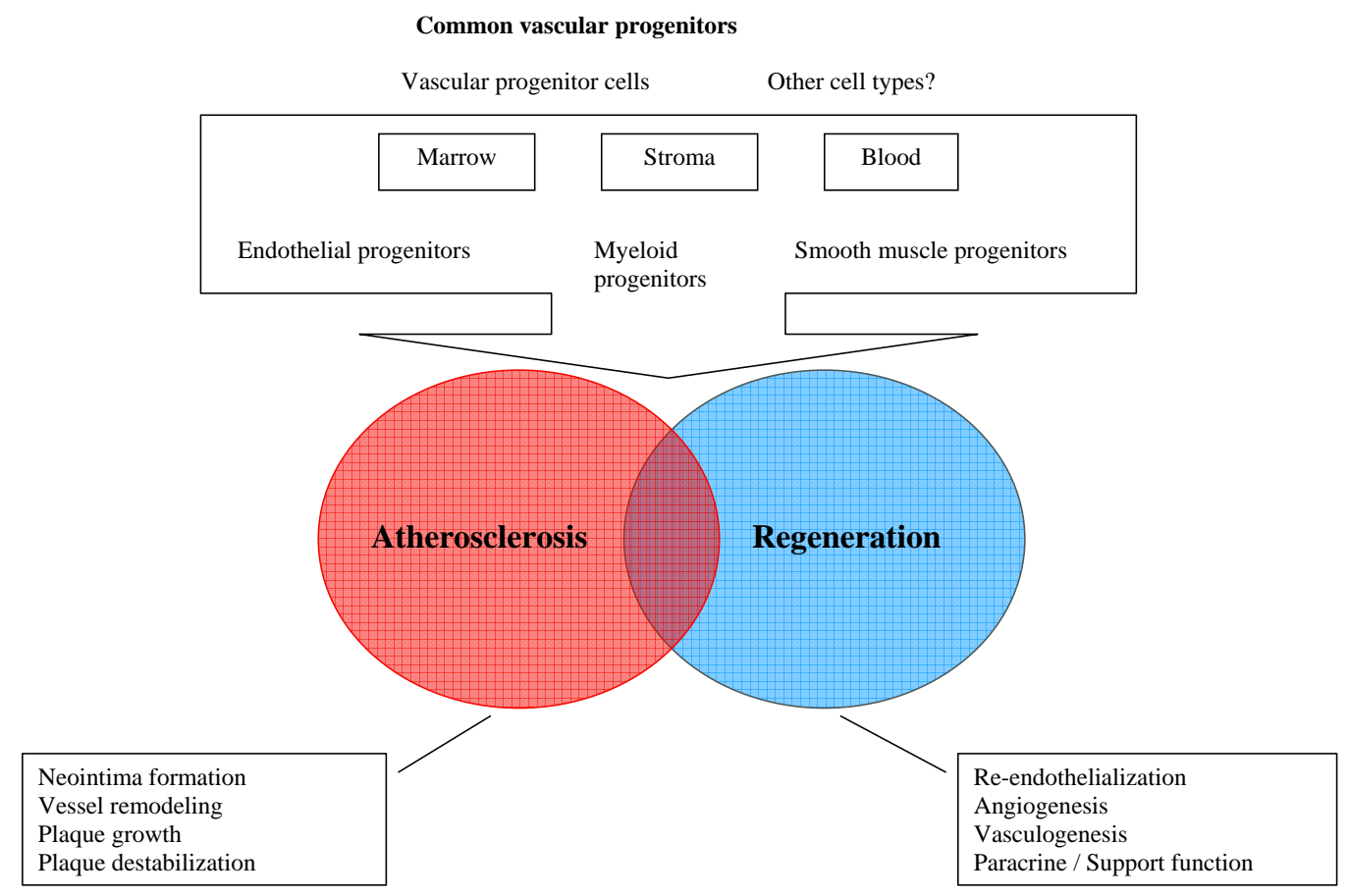

Fig. (1). Schematic presentation of progenitor cells involvement in vessels regeneration and atherosclerosis progression.

tional effects of stem cells in pathological conditions in humans, including chronic and acute atherosclerotic disease and chronic heart failure.

Cardiovascular risk factors [22], type of tissue injury [2325] and the use of medications [26] - all these may have an impact on both stem cell functional status and abilities of affected tissues to host reparative cells. Chronic inflammation and oxidative stress could switch stem/progenitor cellguided regenerative pathway into pro-inflammatory and proatherogenic direction, resulting in monocyte and immune cells recruitment to vascular wall where they maturate into neointima smooth muscle cells [27]. Cardiovascular medications, such as statins, angiotensin II type I receptor blockers and PPAR-gamma agonists, exhibit favorable effects on human stem cells cultured in vitro, increasing their survival and ability to regenerate ischemic tissues in animal models [26]. It is not clear, whether these medications modulate stem cell effects on atheroma growth and plaque destabilization, however studies suggest favorable effect of angiotensin II type 1 receptor blockers [28].

Here we review the major outstanding questions on the stem cells translational roadmap in cardiovascular regeneration, including controversies in stem cell definitions, mechanisms of stem cell trafficking and homing and stem cell role in atherosclerosis progression.

\section{DEFINITIONS OF ENDOGENOUS STEM/ PROGENITOR CELLS}

Stem and progenitor cells are immature cells with high self-renewal potential and ability to differentiate into various cell types $[1,8]$. Definition of stem/progenitor cells relies on three categories of methodological assessments: 1) proliferation, self-renewal and differentiation in culture, 2) expres- sion of various molecular markers, 3) ability to execute specialized cell effects, eg, to restore the function of damage tissue/organ after transplantation [29]. The sine qua non criteria of regenerative efficacy of stem/progenitor cells in humans are their good performance in animal transplantation assay [29]. However, the results obtained in animal models are not always transferable to humans. In order to overcome this shortage several groups have introduced the conception of humanized mice, in which various kinds of human cells and tissues are engrafted into experimental mice models to reconstitute human immune system and other functions in the model [30].

The prototypes of human stem cells are embryonic stem cells - pluripotent cells able to differentiate into all cell types of adult organism. Due to allogeneic nature of cell transplantation, possibility of tumorogenesis and ethical issues embryonic stem cells are not widely used for therapeutic purposes, however, the first human trial using embryonic stem cells as a medical treatment has been approved recently by US Food and Drug Administration [31]. Recent reports have described reprogramming of adult differentiated cells, such as fibroblasts, into a state of pluripotency [32]. These induced pluripotent stem cells (iPSC) are promising candidates for ischemic tissue regeneration as a potential new source of "embryonic-like" stem cells that overcome the current limitations of embryonic stem cells. However, more robust data are warranted about iPSC trans-differentiation into cardiomyocytes, vascular smooth muscle and endothelial cells in vivo.

Multipotent stem cells are usually responsible for postnatal tissue reparations during physiological turnover, aging or injury [32]. Hematopoietic and mesenchymal stem cells are multipotent stem cells bearing potential for cardiovascular 
regeneration. Hematopoietic stem cells have been isolated from bone marrow, peripheral blood and from umbilical cord blood as CD34+ and CD133+ cells, forming several types of well characterized colonies in culture (erythroid, myeloid, granulocyte-macrophage, etc) [33]. Numerous studies of bone marrow transplantation in hematological malignancies in humans have shown donor stem cell repopulation of recipient's bone marrow and restoration of haematopoietic function [34].

Mesenchymal stem cells reside predominantly in bone marrow stroma [35]. Their main function is maintenance of marrow mesenchymal stromal cell pool in stromal niche to support quiescent hematopoietic stem cells [35]. Mesenchymal stem cells could also differentiate into adipocytes, osteoblasts, chondrocytes and myoblasts. These cells do not express traditional hematopoietic and leukocytic markers CD34, CD133, CD45 and HLA-DR, but could be characterized by expression of CD105, CD73 and CD90 and ability to adhere to plastic (in culture) and bind variety of adhesion molecules [35, 36]. Due to their non-immunogenic nature, mesenchymal stem cells could be used for allogenous cell therapy [36]. Recent work has described their adjuvant role in supporting vasculogenesis via secretion of angiogenic factors and recruitment of reparative stem cells to the site of injury [37]. Their ability for cardiogenic differentiation has also been reported [38]. Clinical studies on the use of mesenchymal stem cells for cardiac regeneration after myocardial infarction are underway [37]. Stem cells, harvested from adipose tissue, have been also found to express adhesion molecules and hence to have potential to facilitate reparative stem cells tissue engraftment [39]. Experimental data indicate that adipose derived stem cells ameliorate tissue ischemia, increase tissue capillary density and differentiate into capillary structures in vitro [39].

Smooth muscle progenitor cells have been described as bone marrow resident and circulating cells that express markers of mesenchymal/smooth muscle lineage, such as endoglin (CD105), calponin and a-smooth muscle albumin (a-SMA) [40]. There are some controversies in phenotypic definition of smooth muscle progenitor cells. Smooth muscle cells are a highly heterogeneous cell population with different characteristics and markers and hence their predecessors may have distinct phenotypes in physiological and pathological conditions [41].

It is clear now that both endothelial and smooth muscle cells could originate from the same paternal cells, such as common vascular progenitor cells. Indeed, peripheral blood myeloid subset of CD14+CD105+ cells have been shown to be able to differentiate in culture into endothelial-like and smooth muscle cell-like lineage depending on culture conditions [14]. In enhanced green fluorescence protein (EGFP) transgenic mice model, EGFP labeled cells, injected after femoral artery wire injury, have been found in both neointima and media of injured artery [42]. These cells stained positively for both endothelial marker CD31 and a-SMA, implying the presence of a cohort of cells able to maturate in vivo into both endothelial and smooth muscle cells [42].

Much discussed is the question how endogenous smooth muscle progenitor cells regulate atherosclerosis progression $[21,41]$. Animal studies with progenitor cell transplantation provided ambiguous data. Studies have shown that smooth muscle progenitor cells are present in atherosclerotic plaque caps, neointima, media and adventitia of injured vessels [21]. Local inhibition of smooth muscle progenitor cells adhesion after arterial injury was reported to attenuate neointimal progression [42]. At the same time, recruitment of smooth muscle progenitor cells in chronic advanced atherosclerosis was shown to aid in stable plaque maintenance [43].

Skeletal myoblasts and resident cardiac stem cells are considered as capable to differentiate into mature cardiocytes $[44,45]$. However, clinical studies with myoblast injections into cardiac muscle have shown increased risk of cardiac arrhythmias [44]. Intense research is conducted on isolation, expansion and differentiation of resident cardiac stem cells [45]. Recent study has reported isolation of c-kit+ cardiac stem cells from human right atrium [46]. The major obstacle in the laboratory expansion of resident cardiac stem cells is the need for cardiac biopsy in order to harvest the cells. However, for high risk patients undergoing cardiac surgery, harvesting c-kit+ cells from right atrium could be justifiable, if adequate expansion protocol is developed and their transplantation efficacy is proven.

\section{CONTROVERSIES IN CHARACTERIZATION OF ENDOTHELIAL PROGENITOR CELLS AND EMERGING ROLE OF MYELOID PROGENITORS IN CARDIOVASCULAR REGENERATION}

There is no consensus yet regarding definitions of distinct cell types committed to postnatal angiogenesis and ischemic tissue regeneration. One of the most controversial topics is phenotypic and functional characterizations of endothelial progenitor cells.

Hematopoietic and non-hematopoietic vasculogenic progenitor cells are originating from common embryonic predecessor hemangioblast [47]. Hence, Asahara et al. suggested that circulating bone marrow-derived hematopoietic CD34+ cell population could contain subset of cells, maturating into endothelial cells and assisting in postnatal vasculogenesis [4, 48]. Subsequent studies have adopted the term "endothelial progenitor cells" and applied it to circulating and bone marrow resident cells, co-expressing hematopoietic (CD34, CD133) and endothelial markers, such as VEGF receptor-2 (VEGFR2), CD31, Tie-2, vascular endothelial (VE) cadherin and endothelial nitric oxide synthase (eNOS) [12, 49, 50]. Numerous animal studies have shown ability of circulating and marrow-derived cells to enhance ischemic tissue revascularization. However, most of the studies have transplanted non-selective bone marrow cell populations rather then cell subsets, co-expressing hematopoietic and endothelial antigens, forming endothelial-like colonies in culture. Recent study, however, have demonstrated improvement of cardiac function after intracoronary injection of CD34+chemokine receptor 4 (CXCR4)+ cells in humans [51].

Unfortunately, mentioned phenotypic markers could not accurately discriminate endothelial progenitor cells, as various cell types share the same antigens. For example, CD14+ myeloid subsets express CD34 and CD133, as well as VEGFR2, Tie-2 and other endothelial markers [15, 16, 52]. Circulating mature endothelial cells are co-expressing CD34 and various endothelial antigens. Peichev et al. [53] suggested to use a three antigen based (CD34, VEGFR2, and 
CD133) protocol to separate circulating putative endothelial progenitor cells. However, recent work has demonstrated that triple positive CD34+CD133+VEGFR2+ cell population is hematopoietic, but not an endothelial progenitor [54]. CD34+CD133+VEGFR2+ enriched cells formed hematopoietic colonies, but not endothelial cell like structures in vitro [54]. Progenitor cells co-expressing hematopoietic and endothelial markers have not been utilized for vascular regenerative therapy in humans and hence their transplantation effects are not known.

In addition to surface antigen defining techniques, two major culture-based approaches have been proposed to identify endothelial progenitor cells $[49,50,55]$. In so called early colony forming unit (CFU) [49] assay mononuclear cells are plated on fibronectin coated plates; after few days of culture non-adherent cells are removed and adherent cells are remaining in culture for the next 5-7 days. In late outgrowth endothelial cell (OEC) assay mononuclear cells are let to grow for 14-21 days forming characteristic cobblestone colonies. Cells in early colonies are positive for both endothelial and myeloid progenitor cell markers and maturate into macrophages that express non-specific esterase and ingest bacteria [56]. Their progeny fail to form human-like blood vessels when implanted into immunodeficient mice [56]. In contrast, cells in OEC do not express CD14 and other myeloid markers, they are characterized by higher proliferative capacity, could form capillary-like structures in vitro and participate into vasculogenesis in mice models in vivo [57]. Therefore, OEC assay, most likely, is identifying vascular or, more specifically, endothelial cell progeny, whereas, early colony assay - monocytic/macrophage cell lineage. Indeed, fibronectin coated plates culture techniques are used to isolate circulating monocytes [58]. In addition, circulating CD14+CD45+ monocytes and tissue macrophages have been shown to exhibit endothelial-like cell features, such as uptake of acetylated low density lipoprotein, binding ulex lectin and expressing of eNOS [59].

Clinical studies, exploring association between cardiovascular risks and circulating progenitor cells, have utilized both culture techniques to measure progenitor cell clonogenic potential. Most of the studies have reported inverse relationship between circulating endothelial progenitor cell number and severity of cardiovascular disease [12, 50]. Thus, it is plausible, that both early and late colony forming subsets of circulating progenitor cells play a role in cardiovascular regeneration.

It was reported, that CD14+ myeloid subsets isolated from peripheral blood formed morphologically identical to early endothelial progenitor cell colonies in culture, and, when injected intravenously in mice with hindlimb ischemia, improved muscle perfusion and increased capillary density $[16,52]$. Subpopulation of monocyte-derived CD34+/ CD14+, CD14+VEGFR2+CXCR2+ and Tie2+CD14+CD16+ cells, releasing angiogenic growth factors, and directly incorporating into neo-endothelium, has also been described [12].

Under conditions of vascular ischemia mobilized subsets of hematopoietic progenitor cells could undergo "alternative activation pathway", maturating into non-inflammatory macrophages and dendritic cells, able to migrate through the endothelial barrier into the matrix of the tissue [12]. These migrated cells have been shown to foster local production of innate immune cells and to release chemotactic and growth factors stimulating recruitment of circulating and tissue resident progenitor cells to the site of injury aiming to preserve homeostasis of healthy vessels [60]. Ex vivo activation of monocytes chemoattractant protein-1 stimulates adhesion of bone marrow-derived monocyte-like cells to injured arteries, resulting in re-endothelialization and reduction in neointima formation [52].

\section{STEM/PROGENITOR CELL TRAFFICKING AND HOMING}

Regenerative effect of all non-tissue-resident stem/ progenitor cells, including exogenously administered cells, depends on their recruitment into the site of injury. This process is regulated by molecular signals from damaged tissue and schematically could be presented as stem cells mobilization, migration with circulating blood and tissue engraftment including in situ proliferation and differentiation [61].

Many details of hematopoietic cells trafficking from bone marrow to ischemic non-marrow tissues have been clarified in experimental animal models. Responding to the signals from the periphery stem/progenitor cells migrate within bone marrow from the steady-state stromal niche into the vascular compartment and then are released into circulating blood [61]. The most powerful signal for stem cells mobilization and homing is chemokine stromal cell derived factor- 1 (SDF-1 also known as CXCL12), which binds to its specific receptor $\mathrm{CXC4}$ [62].

In normal hematopoiesis SDF-1 plays a crucial role for circulating stem cell homing to bone marrow [62]. In physiological conditions various tissues, including bone marrow stroma, constitutively express SDF-1 [62]. In absence of injury in peripheral tissues, there is a significant gradient between concentration of SDF-1 in bone marrow and in peripheral tissues [62]. During hypoxia, ischemia and inflammation SDF-1 is up-regulated and marrow-tissue SDF-1 gradient is reversed [63-65]. Activated platelets express SDF-1 and hence contribute to the recruitment of circulating progenitor cells to the growing platelet thrombi on the site of arterial injury. The gene expression of SDF-1 is regulated by the transcription factor hypoxia-inducible factor-1 (HIF-1) [66]. The expression of HIF-1 is up-regulated in hypoxic, injured and ischemic tissues and recruitment of regenerative CXCR4+ progenitor cells is mediated by hypoxic gradients via HIF-1-induced expression of SDF-1 [66]. During ischemia or inflammation VEGF, erythropoietin, granulocytecolony stimulating factor (G-CSF) and nitric oxide (NO) exert mobilizing action on hematopoietic stem cells in part via SDF-1 route [62-66]. Mobilization of progenitor cells to the site of injury was significantly impaired in eNOS knockout mice [67]. SDF-1 induces the release of NO in endothelial cells, creating positive feedback loops for regenerative cells chemotaxis [66-68]. Recent reports have shown involvement of Notch and sphingosine-1 phosphate system signaling in the activation of CXCR4 under conditions of tissue ischemia [68]. Clinical studies have demonstrated, that cardiovascular surgical intervention had mobilizing effect on CD34+, CD34+CXCR4+ cells and increased number of circulating CFU progenitor cells [69]. 
In addition to SDF-1-CXCR4+ axis, important role in stem cells recruitment to tissue play soluble or surface arrested angiogenic $\mathrm{CC}$ - and inflammatory $\mathrm{CXC}$-chemokines (CCL2, CXCL1, CXCL7) and their respective receptors (CCR2, CXCR2, CXCR4) on stem/progenitor cell surface [68]. In particular, up-regulation of CXCR2 ligands CXCL1 and CXCL7 during arterial injury resulted in selective recruitment of myeloid CD14+ vascular progenitor subsets to sites of injury, increasing of re-endothelialization [70].

\section{ATHEROSCLEROSIS PROGRESSION VERSUS ENDOTHELIAL RECOVERY: CONTRIBUTION OF STEM/PROGENITOR CELLS}

Development of atherosclerotic lesions depends on continuous focal inflammation initiated by endothelial damage, followed by sub-endothelial accumulation of lipids and immune cells. Local resident macrophages release a host of pro-inflammatory Th1-type cytokines (gamma interferon, tumor necrosis factor alpha and interleukin (IL)-2), which quickly recruit circulating inflammatory and immune mononuclear cells to subendothelial matrix, perpetuating inflammatory vicious circle [60]. At the same time, as a compensatory reparation response, macrophages undergo alternative activation (develop into M2 type cells) to support vessel healing [71]. M2 cells secrete Th2-type cytokines and chemokines (IL-3, IL-8, G-CSF, etc), which mediate mobilization of regenerative progenitor cells [71]. Upon atherosclerosis progression critical reduction in blood flow triggers compensatory angiogenesis to diminish tissue ischemia. Molecular stimuli from ischemic tissues attract bone marrow' and circulating stem/progenitor cells. Adequate endothelial regeneration is crucial for prevention of atheroma growth [61]. Studies on chimeric animals carrying EGFP positive bone marrow cells have demonstrated that these cells contribute to endothelial repair after injury [42]. Transfusion of healthy wild-type mice bone marrow-derived cells into atherosclerotic Apolipoprotein E-knockout $\left(\mathrm{ApoE}^{-/}\right)$mice lead to improvement in endothelial function and inhibited atherosclerosis progression [72]. Over-expression of angiogenic CC-chemokine L2 in infused bone marrow mononuclear cells significantly reduced neointima formation and accelerated re-endothelialization via recruitment of CCR2+ progenitor cells [52]. It is well known that inhibition of proinflammatory macrophage migration into atherosclerotic lesions leads to a more stable plaque phenotype. Recent study reported that blockage of monocyte inflammatory factor, which regulates both macrophage migration and CXCR4 and CXCR2 expression, resulted in reduced neointima area [73].

However, in contrast to antiatherogenic effects, circulating and marrow-resident stem/progenitor cells participate in vessel remodeling and plaque angiogenesis, supporting atherosclerosis progression. It has been demonstrated, that infused progenitor cells in $\mathrm{ApoE}^{-/-}$mice increased plaque size and converted its phenotype to unstable one [74]. In vivo seeding of CD34+ progenitor cells to the surface of a graft stimulated neointimal hyperplasia [5].

The contribution of stem/progenitor cells to atherosclerosis progression has been confirmed in numerous studies utilizing animal models of transplant atherosclerosis and bone marrow transplantation in conjunction with vascular injury.
Donor-derived smooth muscle cells were identified within the atherosclerotic vessel wall in patients after sexmismatched bone marrow transplantation [75]. It appears that cellular constituents of vascular lesions vary with the type of injury (primary atherosclerosis, post-angioplasty restenosis or intimal hyperplasia of vein graft) [76]. This has been studied in detail in animal bone marrow transplantation vascular injury model studies. It was shown that type of vascular injury (wire injury, vessel ligation, perivascular cuff induced trauma) determined the number of bone marrow cells migrated to neointima [42]. The largest numbers of transplanted bone marrow derived cells was found in neointima after wire injury with vessel wall dilatation and endothelial denudation (injury, which share similarities with angioplasty procedure in humans) [42]. Interestingly, the degree of vessel injury-related inflammation (irrespective from the type of injury) did not intervene with the contribution of bone marrow derived cells to the neointima [42].

The source of progenitor cells conferring proatherogenic effects (such as neointima growth) remains a matter of debate. Transplant atherosclerosis animal studies have shown that endothelial cells of microvessels within allograft atherosclerotic vessels are derived from recipient bone marrow progenitor cells [77]. At the same time, it was shown, that Sca+lin- progenitor cells in allograft vessels have migrated from adventitia to the neointima, were they maturated into smooth muscle cells [78]. Furthermore, it was reported, that smooth muscle cells in advanced atherosclerosis have originated from the vessel wall and healing after plaque rupture mainly involved local, but not circulating cells [43].

Molecular mechanisms of endogenous progenitor cell contribution to atherosclerosis are not well understood. The evidence is emerging about the role of SDF-1/CXCR4 and CXCL1/CXCR2 axes [27]. However, there are controversies between different studies.

It was suggested that SDF-1 may have plaque stabilizing effects [79]. It was found that smooth muscle and endothelial cells in stable plaques express SDF-1 and patients with unstable coronary artery disease have reduced levels of SDF1 in plasma [80]. At the same time, it has been shown, that blocking of SDF-1 resulted in significant reduction of neointima formation after arterial injury in $\mathrm{ApoE}^{-/-}$mice, implicating SDF-1 role in vessel remodeling [79]. Notably, blocking of SDF-1 in the same study did not reduce re-endothelialization after injury [79]. Continuous blockage of SDF-1 receptor CXCR4 resulted in aggravation of atherosclerosis in mice via increasing homing of neutrophils, whereas, smooth muscle progenitor cells recruitment was not changed [81]. In contrast, recent work has shown that treatment with CXCR4 antagonist decreased neointima formation and smooth muscle cell mobilization after arterial injury, however had no effect on reendothelialization after endothelial denudation [82].

Blockage of CXCR2 ligand CXCL1 inhibited endothelial recovery and increased neointima growth in $\mathrm{ApoE}^{-/-}$mice after wire injury in the carotid artery [83]. Neointima macrophages were identified as a major source of CXCL1 in injured vessels in $\mathrm{ApoE}^{-/-}$mice [83]. It is established, that CXCL1 promotes atherogenesis through increased recruitment of monocytes [83]. Increased levels of CXCR2 ligands 
CXCL1 and CXCL7 were related in clinical studies with plaque destabilization and blockage of CXCR2 was associated with stable plaque phenotype [42].

Thus, it appears that molecular stimuli which regulate atherosclerosis progression coordinate vessel wall engraftment of both progenitor and inflammatory cells. It is likely, that widespread chronic recruitment of myeloid progenitors could potentiate atherosclerosis progression via maintanence of continous inflammation and plaque neovascularization. In parallel, recruitment of progenitor cells giving rise to smooth muscle cells within atherosclerotic plaque could maintain plaque stability. In acute vessel injury, recruitment of progenitor cells able to restore endothelial layer may support vessel recovery.

\section{CONCLUSIONS}

Recent developments in stem cells research have revealed new facts about biology of endogenous stem/ progenitor cells in humans. Phenotypic and functional plasticity of bone marrow resident and circulating stem/ progenitor cells has been increasingly appreciated. Therefore, there is a need to put even more efforts to develop methodologies able to identify distinct cell types prospectively or to predict reparative effects of endogenous mobilized or exogenously administered cells. The contribution of stem/progenitor cells to atherosclerosis progression and vascular remodeling after injury in humans is established, however many details are still unknown. It is hoped that future studies would explore ambivalent role of stem cells in tissue regeneration and in atherosclerosis progression. In the respect of the main clinical endpoint, it is important to get selective control over specific patient-related factors that may have an impact on cell therapy outcome, such as severity of atherosclerosis, cardiovascular risk factors and co-morbid background.

\section{REFERENCES}

[1] Seiler C. The human coronary collateral circulation. Heart 2003; 89: $1352-7$.

[2] Barner HB. Operative treatment of coronary atherosclerosis. Ann Thorac Surg 2008; 85: 1473-82.

[3] Rafii S, Lyden D. Therapeutic stem and progenitor cell transplantation for organ vascularization and regeneration. Nat Med 2003; 9:702-12.

[4] Asahara T, Masuda H, Takahashi T, et al. Bone marrow origin of endothelial progenitor cells responsible for postanatal vasculogenesis in physiological and pathological neovascularization. Circ Res 1999; 85: 221-8.

[5] Bhattacharya V, McSweeney PA, Shi Q, et al. Enhanced endothelialization and microvessel formation in polyester grafts seeded with $\mathrm{CD} 34^{+}$bone marrow cells. Blood 2000; 95: 581-5.

[6] Sata M. Role of circulating vascular progenitors in angiogenesis, vascular healing and pulmonary hypertension: lessons form animal models. Atherioscler Thromb Vasc Biol 2006; 26: 1008-14.

[7] Orlic D, Kajstura J, Chimenti S, et al. Mobilized bone marrow cells repair the infarcted heart, improving function and survival. Proc Natl Acad Sci 2001; 98: 10344-9.

[8] Dimmeler S, Burchfield J, Zeiher AM. Cell-based therapy of myocardial infarction. Arterioscler Thromb Vasc Biol 2008; 28: 20816.

[9] Martin-Rendon E, Brunskill SJ, Hyde CJ, Stanworth SJ, Mathur A, Watt SM. Autologous bone marrow stem cells to treat acute myocardial infarction: a systematic review. Eur Heart J 2008; 29: 180718.

[10] Schächinger V, Erbs S, Elsässer A, et al. Improved clinical outcome after intracoronary administration of bone-marrow-derived progenitor cells in acute myocardial infarction: final 1-year results of the REPAIR-AMI trial. Eur Heart J 2006; 27: 2775-83.

[11] Kovacic JC, Harvey RP, Dimmeler S. Cardiovascular regenerative medicine: digging in for the long haul. Cell Stem Cell 2007; 1: 628-33.

[12] Yoder MC. Defining human endothelial progenitor cells. J Thromb Haemost 2009; 7: 49-52.

[13] Sugiyama S, Kugiyama K, Nakamura S, et al. Characterization of smooth muscle-like cells in circulating human peripheral blood. Atherosclerosis 2006; 187: 351-62.

[14] Metharom P, Liu C, Wang S, et al. Myeloid lineage of high proliferative potential human smooth muscle outgrowth cells circulating in blood and vasculogenic smooth muscle-like cells in vivo. Atherosclerosis 2008; 198: 29-38.

[15] Rohde E, Malischnik C, Thaler D, et al. Blood monocytes mimic endothelial progenitor cells. Stem Cells 2006; 24: 357-67.

[16] Urbich C, Heeschen C, Aicher A, Dernbach E, Yeiher A, Dimmerler S. Relevance of monocytic features for neovascularization capacity of circulating endothelial progenitor cells. Circulation 2006; 108: 2511-6.

[17] Tsai S, Butler J, Rafii S, Liu B, Kent KC. The role of progenitor cells in the development of intimal hyperplasia. J Vasc Surg 2009; 49: 502-10.

[18] Hristov M, Zernecke A, Schober A, Weber C. Adult progenitor cells in vascular remodeling during atherosclerosis. Biol Chem 2008; 389: 837-44

[19] Di Stefano R, Felice F, Balbarini A. Angiogenesis as risk factor for plaque vulnerability. Curr Pharm Des 2009; 15: 1095-106.

[20] Torsney E, Mandal K, Halliday A, Jahangiri M, Xu Q. Characterisation of progenitor cells in human atherosclerotic vessels. Atherosclerosis 2007; 191: 259-64.

[21] Hristov M, Weber C. Ambivalence of progenitor cells in vascular repair and plaque stability. Curr Opin Lipidol 2008; 19: 491-7.

[22] Vasa M, Fichtlscherer S, Aicher A, Adler K, Urbich C, Martin H. Number and migratory activity of circulating endothelial progenitor cells inversely correlate with risk factors for coronary artery disease. Circ Res 2001; 89: E1-E7.

[23] Thomas H, Avery P, Ahmed J, Edwards R, Purcell I, Zaman A. Local vessel injury following percutaneous coronary intervention does not promote early mobilization of endothelial progenitor cells in the absence of myocardial necrosis. Heart 2009; 95: 555-8.

[24] Wojakowski W, Kucia M, Kazmierski M, Ratajczak M, Tendera M. Circulating progenitor cells in stable coronary heart disease and acute coronary syndromes: relevant reparatory mechanisms? Heart 2008; 94: 27-33.

[25] Kopp HG, Ramos CA, Rafii S. Contribution of endothelial progenitors and proangiogenic hematopoietic cells to vascularization of tumor and ischemic tissue. Curr Opin Hematol 2006; 13: 175-81.

[26] Besler C, Doerries C, Giannotti G, Lüscher TF, Landmesser U. Pharmacological approaches to improve endothelial repair mechanisms. Expert Rev Cardiovasc Ther 2008; 6: 1071-82.

[27] Zernecke A, Shardarsuren E, Weber C. Chemokines in atherosclerosis: an update. Arterioscler Thromb Vasc Biol 2008; 28: 18971907.

[28] Yamada T, Kondo T, Numaguchi Y, Tsuzuki M, Matsubara T, Manabe I. Angiotensin II receptor blocker inhibits neointimal hyperplasia through regulation of smooth muscle-like progenitor cells. Arterioscler Thromb Vasc Biol 2007; 27: 2363-9.

[29] van Os R, Kamminga LM, de Haan G. Stem cell assays: something old, something new, something borrowed. Stem Cells 2004; 22: $1181-90$

[30] Pearson T, Greiner DL, Shultz LD. Humanized SCID mouse models for biomedical research. Curr Top Microbiol Immunol 2008; 324: $25-51$.

[31] Lui KO, Waldmann H, Fairchild PJ. Embryonic stem cells: overcoming the immunological barriers to cell replacement therapy. Curr Stem Cell Res Ther 2009; 4: 70-80.

[32] Jaenish R, Young R. Stem cells, the molecular circuitry of pluripotency and nuclear reprogramming. Cell 2008; 132: 567-82.

[33] Gallacher L, Murdoch B, Wu DM, Karanu FN, Keeney M, Bhatia $\mathrm{M}$. Isolation and characterization of human CD34(-)Lin(-) and CD34(+)Lin(-) hematopoietic stem cells using cell surface markers AC133 and CD7. Blood 2000; 95: 2813-20.

[34] Chan RJ, Yoder MC. The multiple facets of hematopoietic stem cells. Curr Neurovasc Res 2004; 1: 197-206. 
[35] Chamberlain G, Fox J, Ashton B, Middleton J. Concise review: mesenchymal stem cells: their phenotype, differentiation capacity, immunological features, and potential for homing. Stem Cells 2007; 25: 2739-49.

[36] Gnecchi M, Melo LG. Bone marrow-derived mesenchymal stem cells: isolation, expansion, characterization, viral transduction, and production of conditioned medium. Methods Mol Biol 2009; 482: 281-94.

[37] Psaltis PJ, Zannettino A, Worthley SG, Gronthos S. Mesenchymal stromal cells - potential for cardiovascular repair. Stem Cells 2008; 26; 2201-10.

[38] Toma C, Pittenger MF, Cahill KS, Byrne BJ, Kessler PD. Human mesenchymal stem cells differentiate to a cardiomyocyte phenotype in the adult murine heart. Circulation 2002; 105: 938.

[39] Sanz-Ruiz R, Fernández-Santos E, Domínguez-Muñoa M, et al. Early translation of adipose-derived cell therapy for cardiovascular disease. Cell Transplant 2009; 18: 245-54.

[40] Simper D, Stalboerger PG, Panetta CJ, Wang S, Caplice NM. Smooth muscle progenitor cells in human blood. Circulation 2002; 106: 1199-204.

[41] Margariti A, Zeng L, Xu Q. Stem cells, vascular smooth muscle cells and atherosclerosis. Histol Histopathol 2006; 21: 979-85.

[42] Tanaka K, Sata M, Hirata Y, Nagai R. Diverse contribution of bone marrow cells to neointimal hyperplasia after mechanical vascular injuries. Circ Res 2003; 93: 783-90.

[43] Zoll J, Fontaine V, Gourdy P, et al. Role of human smooth muscle cell progenitors in atherosclerotic plaque development and composition. Cardiovasc Res 2008; 77: 471-80.

[44] Sherman W, He KL, Yi GH, et al. Myoblast transfer transfer in ischemic heart failure: effects on rhythm stability. Cell Transplant 2009; 18: 333-41.

[45] van Vliet P, Sluijter JP, Doevendans PA, Goumans MJ. Isolation and expansion of resident cardiac progenitor cells. Expert Rev Cardiovasc Ther 2007; 5: 33-43.

[46] Aghila RKG, Jayakumar K, Srinivas G, Nair RR, Kartha CC. Isolation of cKit-positive cardiosphere-forming cells from human atrial biopsy. Asian Cardiovasc Thorac Ann 2008; 16: 50-56.

[47] Ribatti D. Hemangioblast does exist. Leuk Res 2008; 32: 850-4.

[48] Asahara T, Murohara T, Sullivan A, et al. Isolation of putative progenitor endothelial cells for angiogenesis. Science 1997; 275 : 964-7.

[49] Hill JM, Zalos G, Halcox JP, et al. Circulating endothelial progenitor cells, vascular function, and cardiovascular risk. N Engl J Med 2003; 348: 593-600.

[50] Urbich C, Dimmeler S. Endothelial progenitor cells: characterization and role in vascular biology. Circ Res 2004; 95: 343-53.

[51] Tendera M, Wojakowski W, Ruzyłł W, et al. Intracoronary infusion of bone marrow-derived selected CD34+CXCR4+ cells and non-selected mononuclear cells in patients with acute STEMI and reduced left ventricular ejection fraction: results of randomized, multicentre Myocardial Regeneration by Intracoronary Infusion of Selected Population of Stem Cells in Acute Myocardial Infarction (REGENT) Trial. Eur Heart J 2009; 30: 1313-21.

[52] Fujiyama S, Amano K, Uehira K, et al. Bone marrow monocytes lineage cells adhere on injured endothelium in a monocytes chemoattractant protein-1-dependent manner and accelerate reendothelialization as endothelial progenitor cells. Circ Res 2003; 93: 980-9.

[53] Peichev M, Maiyer A, Pereira D, et al. Expression of VEGFR-2 and AC133 be circulating human CD34(+) cells identifies a population of functional endothelial precursors. Blood 2000; 95: 952-8.

[54] Case J, Mead LE, Bessler WK, et al. Human CD34 ${ }^{+} \mathrm{AC} 133^{+}$ VEGFR2 $^{+}$cells are not endothelial progenitor cells but distinct, primitive hematopoietic progenitors. Exp Hematol 2007; 35: 110918.

[55] Sieveking DP, Buckle A, Celermajer DS, Ng MK. Strikingly different angiogenic properties of endothelial progenitor cell subpopulations: insights from a novel human angiogenesis assay. J Am Coll Cardiol 2008; 51: 660-8.

[56] Yoder M, Mead L, Prater D, et al. Redefining endothelial progenitor cells via clonal analysis and hematopoietic stem/progenitor cell principals. Blood 2007; 109: 1801-9.

[57] Timmermans F, Van Hauwermeiren F, De Smedt M, et al. Endothelial outgrowth cells are not derived from $\mathrm{CD}_{133^{+}}$cells or CD45 hematopoietic precursors. Arterioscler Thromb Vasc Biol 2007; 27 : 1572-9.

[58] Freundlich B, Avdalovic N. Use of gelatin/plasma coated flasks for isolating human peripheral blood monocytes. J Immunol Methods $1983 ; 62: 31-7$.

[59] Liu C, Wang S, Metharom P, Caplice N. Myeloid lineage of human endothelial outgrowth cells circulating in blood and vasculogenic endothelial-like cells in the diseased vessel wall. J Vasc Res 2009; 46: 581-91.

[60] Bosco MC, Puppo M, Blengio F, et al. Monocytes and dendritic cells in a hypoxic environment: Spotlights on chemotaxis and migration. Immunobiology 2008; 213: 733-49.

[61] Hristov M, Weber C. Progenitor cell trafficking to the vessel wall. J Thromb Hemost 2009; 7: 31-4.

[62] Lataillade JJ, Domenech J, Le Bousse-Kerdiles MC. Stromal cellderived factor-1 (SDF-1)/CXCR4 couple plays multiple roles on hematopoietic progenitors at the border between the old cytokine and new chemokine worlds: survival, cell cycling and trafficking. Eur Cytokine Net 2004; 15: 177-88.

[63] Petit I, Jin D, Rafii S. The SDF-1-CXCR4 signaling pathway: a molecular hub modulating neo-angiogenesis. Trends Immunol 2007; 28: 299-307.

[64] Abbott JD, Huang Y, Liu D, Hickey R, Krause DS, Giordano FJ. Stromal cell-derived factor-1 alpha plays a critical role in stem cell recruitment to the heart after myocardial infarction but is not sufficient to induce homing in the absence of injury. Circulation 2004; 110: 3300-5.

[65] Dentelli P, Rosso A, Balsamo A, et al. C-kit, by interacting with the membrane-bound ligand, recruits endothelail progenitor cells to inflamed endothelium. Blood 2007; 109: 4264-71.

[66] Ceradini DJ, Kulkarni AR, Callaghan MJ, et al. Progenitor cell trafficking is regulated by hypoxic gradients through HIF-1 induction of SDF-1. Nat Med 2004; 10: 858-64.

[67] Gallagher KA, Liu ZJ, Xiao M, et al. Diabetic impairments in NOmediated endothelial progenitor cell mobilization and homing are reversed by hyperoxia and SDF-1 alpha. J Clin Invest 2007; 117 : 1249-59.

[68] Zhang CC, Lodish HF. Cytokins regulating hematopoietic stem cell function. Curr Opin Hematol 2008; 15: 307-11.

[69] Dotsenko O, Jahangiri M. Endogenous stem cells in patients undergoing coronary artery bypass surgery. Eur J Cardiothorac Surg 2009 [pii] doi:10.1016/j.ejcts.2009.04.002.

[70] Hristov M, Zernecke A, Bidzhekov K, Liehn EA, Shagdarsuren E, Ludwig A. Importance of CXC chemokine receptor 2 in the homing of human peripheral blood endothelial progenitor cells to sites of arterial injury. Circ Res 2007; 100: 590-7.

[71] Lolmede K, Campana L, Vezzoli M, et al. Inflammatory and alternatively activated human macrophages attract vessel-associated stem cells, relying on separate HMGB1- and MMP-9-dependent pathways. J Leukoc Biol 2009; 85: 779-87.

[72] Xu Q, Zhang Z, Davison F, Hu Y. Circulating progenitor cells regenerate endothelium of vein graft atherosclerosis, which is diminished in apoE-deficient mice. Circ Res 2003; 93: e76e86.

[73] Bernhagen J, Krohn R, Lue H, et al. MIF is a noncognate ligand of $\mathrm{CXC}$ chemokine receptors in inflammatory and atherogenic cell recruitment. Nat Med 2007; 13: 587-96.

[74] George J, Afek A, Abashidze A, et al. Transfer of endothelial progenitor and bone marrow cells influences atherosclerotic plaque size and composition in apolipoprotein E knockout mice. Arterioscler Thromb Vasc Biol 2005; 25: 2636-41.

[75] Caplice NM, Bunch TJ, Stalboerger PG, et al. Smooth muscle cells in human coronary atherosclerosis can originate from cells administered at marrow transplantation. Proc Natl Acad Sci USA 2003; 100: 4754-9.

[76] Zalewski A, Shi Y, Johnson AG. Diverse origin of intimal cells: smooth muscle cells, myofibroblasts, fibroblasts, and beyond? Circ Res 2002; 91: 652-5.

[77] Hu Y, Mayr M, Metzler B, Erdel M, Davison F, Xu Q. Both donor and recipient origins of smooth muscle cells in vein graft atherosclerotic lesions. Circ Res 2002; 91: e13-e20.

[78] Schneeweiss S, Patrick AR, Maclure M, Dormuth CR, Glynn RJ. Abundant progenitor cells in the adventitia contribute to atherosclerosis of vein grafts in apoE-deficient mice. J Clin Invest 2004; 113 : 1258-65. 
[79] Schober A, Knarren S, Lietz M, Lin EA, Weber C. Crucial role of stromal cell-derived factor-1 alpha in neointima formation after vascular injury in apolipoprotein E-deficient mice. Circulation 2003; 108: 2491-7.

[80] Damås JK, Waehre T, Yndestad A, et al. Stromal cell-derived factor-1alpha in unstable angina: potential antiinflammatory and matrix-stabilizing effects. Circulation 2002; 106: 36-42.

[81] Zernecke A, Bot I, Djalali-Talab Y, et al. Protective role of CXC receptor 4/CXC ligand 12 unveils the importance of neutrophils in atherosclerosis. Circ Res 2008; 102: 209-17.
[82] Karshovska E, Zagorac D, Zernecke A, Weber C, Schober A. A small molecule CXCR4 antagonist inhibits neointima formation and smooth muscle progenitor cell mobilization after arterial injury. J Thromb Haemost 2008; 6: 1812-5.

[83] Liehn EA, Schober A, Weber C. Blockade of keratinocyte-derived chemokine inhibits endothelial recovery and enhances plaque formation after arterial injury in ApoE-deficient mice Arterioscler Thromb Vasc Biol 2004; 24: 1891-6.

(C) Olena Dotsenko; Licensee Bentham Open.

This is an open access article licensed under the terms of the Creative Commons Attribution Non-Commercial License (http://creativecommons.org/licenses/ by-nc/3.0/) which permits unrestricted, non-commercial use, distribution and reproduction in any medium, provided the work is properly cited. 